Article

\title{
Ent-homocyclopiamine B, a Prenylated Indole Alkaloid of Biogenetic Interest from the Endophytic Fungus Penicillium concentricum
}

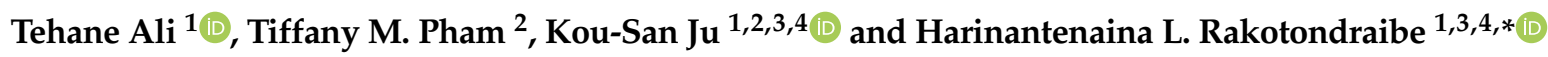 \\ 1 Division of Medicinal Chemistry and Pharmacognosy, College of Pharmacy, The Ohio State University, \\ Columbus, OH 43210, USA; tehane.ali@bayer.com (T.A.); ju.109@osu.edu (K.-S.J.) \\ 2 Department of Microbiology, College of Arts and Sciences, The Ohio State University, Columbus, OH 43210, \\ USA; pham.274@osu.edu \\ 3 Infectious Diseases Institute, The Ohio State University, Columbus, OH 43210, USA \\ 4 Center for Applied Plant Sciences, The Ohio State University, Columbus, OH 43210, USA \\ * Correspondence: rakotondraibe.1@osu.edu; Tel.: +1-614-292-4733
}

Academic Editor: Josphat Matasyoh

Received: 14 December 2018; Accepted: 8 January 2019; Published: 9 January 2019

check for updates

\begin{abstract}
Ent-homocyclopiamine B (1), a new prenylated indole alkaloid bearing an alicyclic nitro group along with 2-methylbutane-1,2,4-triol (2) were isolated from an endophytic fungus Penicillium concentricum of the liverwort Trichocolea tomentella (Trichocoleaceae). The structure of $\mathbf{1}$ was elucidated through extensive spectroscopic analyses and comparison with data reported for a structurally related nitro-bearing Penicillium metabolite, clopiamine C (3), which contain an indolizidine ring instead of the quinolizine ring in $\mathbf{1}$. The new compound, ent-homocyclopiamine B, exhibited slight growth inhibition against Gram-positive bacteria. Based on the reported biosynthesis of related compounds and the isolation of the mevalonic acid derived compound 2-methyl-1,2,4-butanetriol (2), we proposed that ent-homocylopiamine B (1) was biosynthesized from lysine and prenyl group-producing mevalonic pathway.
\end{abstract}

Keywords: liverwort; endophyte; fungus; Penicillium; metabolite; indole alkaloid; antimicrobial

\section{Introduction}

Endophytes are microorganisms (bacteria and fungi) that live within plants without causing apparent pathogenic disease symptoms. Although researchers are seeking to understand the roles of most endophytes in planta, endophytes are believed to protect plant hosts by producing biologically active molecules, reported to secure growth by biosynthesizing plant hormones (e.g., gibberellins), and to balance plant microbial community by counteracting activities of pathogens. It is obvious that plants acquire their endophytes from the environment and thus there should not be any difference between endophytic and non-endophytic microbes of the same species. The only dissimilarity is undoubtedly the surrounding environment where they adapt and acquire starting materials for the biosynthesis of their bioactive metabolites that they use for symbiosis. This adaptation makes endophytes capable to produce wide range of compounds when isolated from the host and fermented using various media. Compounds exhibiting antimicrobial, antiviral and antiproliferative activity have been reported from endophytes [1]. We recently described chemical and pharmacological investigations of extracts prepared from a Penicillium (Trichocomaceae) fungus endophytic to the liverwort Trichocolea tomentella (Trichocoleaceae) that led to the isolation of the antifungal griseofulvin, dehydrogriseofulvin, dechlorogriseofulvin, dehydrodechlorogriseofulvin, griseophenones B and C, griseoxanthones, driniopsin $\mathrm{H}$, norlichexanthonealternariol, ethylene glycol 
benzoate, 6-chloro-3,8-dihydroxy-1-methylxanthone, epi-epoxydon, gentisyl alcohol, gentisyl quinone, hydroxychlorogentisyl quinone, chlorogentisyl quinone, bromogentisyl alcohol and the identification of compounds exhibiting antiproliferative activity against hormone-dependent breast cancer cell line (MCF-7) and the human colorectal adenocarcinoma cell line HT-29. In the continuation of our systematic studies aiming to understand the metabolic profile of the same endophytic strain and to isolate new and bioactive compounds, we prepared an extract of its fermentation in brown rice supplemented with sodium fluoroacetate and isolated 2-methylbutane-1,2,3-triol (2) [2] and ent-homocyclopiamine B (1), a nitro containing alicyclic alkaloid. The isolation and the structure elucidation of the new compound, the effect of the supplementation of sodium monofluoroacetate to the media, the biosynthetic pathway of (1) as well as the results of its antimicrobial evaluation will be discussed herein.

\section{Results}

Compound 1 was obtained as white powder and its positive HRESIMS displayed a protonated molecular ion peak at $m / z 482.2643\left([\mathrm{M}+\mathrm{H}]^{+}\right.$which corresponds to a molecular formula of $\mathrm{C}_{27} \mathrm{H}_{35} \mathrm{~N}_{3} \mathrm{O}_{5}$ (calcd for $\mathrm{C}_{27} \mathrm{H}_{36} \mathrm{~N}_{3} \mathrm{O}_{5}{ }^{+}$, 482.2649). The IR spectrum exhibited two characteristic stretches (1589 and $1353 \mathrm{~cm}^{-1}$ ) of a nitro group [3,4]. The UV maxima ( $\lambda \max 206,232,262,270 \mathrm{sh}, 349 \mathrm{~nm}$ ) of 1 were very similar to those observed in clopiamine $C(3)$, a nitro-containing indole alkaloid derivative isolated from a species of the same genus Penicillium (Penicillium sp.) [3]. The ${ }^{1} \mathrm{H}-\mathrm{NMR}$ spectrum displayed four upfielded singlet methyls at $\delta 0.82,0.95,1.40$ and $1.7 \mathrm{ppm}$ (each corresponds to $3 \mathrm{H}$ ), an aromatic methoxyl group $(\delta 3.80, \mathrm{~s}, 3 \mathrm{H})$, two methine protons at $\delta 2.87(\mathrm{~m})$ and $3.17(\mathrm{~m})$, three sets of diastereotopic methylene protons at: $\delta 2.50$ and 2.97 (each doublet, H-5ab); $\delta 3.48$ and 3.15 (each doublet, H-20ab); and $\delta 2.60$ and 2.94 (each doublet, H-24ab), five pairs of methylene protons at $\delta 1.33(\mathrm{~m}, \mathrm{H}-15 \mathrm{a})$ and 2.77 (dt, H-15b), 1.22 (m, H-19a) and 1.99 (dq, H-19b), $\delta 1.25$ (m, H-18a) and 1.68 (qt, H-18b), $\delta 1.58$ (qt, H-17a) and 1.92 (brd, H-17b), $\delta 2.83$ (brd, H-20a) and 2.86 (m, H-20b); and two ortho coupled aromatic protons ( $\delta 6.65$ and $\delta 7.30$, each doublet). The ${ }^{13} \mathrm{C}-\mathrm{NMR}$ spectrum displayed 27 carbon signals corresponding to five methyls (23.5, C-29; 23.7, C-26; 24.4, C-28; 26.8, C-25; and 56.5, C-27), six carbons assignable to a tetrasubstituted aromatic ring (108.4, C-7; 160.2, C-8; 105.2, CH-9; 133.6, CH-10; 122.0, C-11 and 149.9, C-12), four quaternary carbons (62.3, 57.9, 48.8, and 97.2), one of which assignable to a nitro group bearing quaternary carbon, two methines ( $\delta 48.8$ and 57.0), eight $s p^{3}$ hybridized methylenes ( $\delta 21.1, \mathrm{C}-18 ; 26.1$, C-19; 26.9, C-17; 27.2, C-15; 44.7, C-24; 54.1, C-5; 56.0, C-20; and 60.1, C-22), and two carbonyls ascribable to a ketone (192.9, C-6) and an amide carbonyl ( $\delta 183.3, \mathrm{C}-2)$. The ${ }^{1} \mathrm{H}$ and ${ }^{13} \mathrm{C}-\mathrm{NMR}$ data of compound $\mathbf{1}$ were very similar to those of $\mathbf{3}$ except for the presence of an additional set of methylene signals arising from the A-ring of $\mathbf{1}$. Interpretation of the Correlation Spectroscopy (COSY) spectroscopic data concluded that the additional methylene was part of the spin network of a partial structure $-\mathrm{CH}-\mathrm{CH}_{2}-\mathrm{CH}-\mathrm{CH}_{2}-\mathrm{CH}_{2}-\mathrm{CH}_{2}-\mathrm{CH}_{2}$ - (from H-14 to H-20). In addition, the three observed methylene protons $(\delta 3.48$ and 3.15 , each doublet, $J=11.9 \mathrm{~Hz}, \mathrm{H}-22 \mathrm{ab}$; $\delta 2.60$, and 2.94, d, $J=16.1 \mathrm{~Hz}, \mathrm{H}-24 \mathrm{ab}$; and $\delta 2.50$ and 2.97, d, J = 15.6 Hz, H-5ab) of C-22, C24, and C-5 respectively were concluded to be isolated. The allocation of all functionalities present in $\mathbf{1}$ was carried out by comparison of its spectroscopic data with those of clopiamine $C(3)$ as well as interpretation of its $\mathrm{HMBC}$ spectroscopic data.

The presence of a 2,2,-dimethyl-2,3-dihydroquinolin-4(1H)-one was confirmed by the HMBC long-range correlations from $\mathrm{H}-25$ and $\mathrm{H}-26$ to $\mathrm{C}-4$ and $\mathrm{C}-5, \mathrm{H}-5$ to $\mathrm{C}-6$ and $\mathrm{C}-7, \mathrm{OCH}_{3}$ to $\mathrm{C}-8$, the orthocoupled methine proton at $\delta .65(\mathrm{H}-9)$ to $\mathrm{C}-7, \mathrm{C}-8$, and $\mathrm{C}-11$. The presence of 8,8 -dimethyldecahydro$1 \mathrm{H}$-cyclopenta[f]quinolizine in $\mathbf{1}$ instead of 8,8-dimethyldecahydro-1H-cyclopenta[f]indolizine (3) was substantiated by the above-mentioned spin network deduced from the COSY spectrum and the HMBC correlations from H-28/29 to C-1, C-13 and C-14, from H-20 to C-22, from H-22 to C-24, C-14, and C-23. The above data together with the HMBC correlation observed from $\mathrm{H}-10$ to the quaternary carbon at $\delta 62.3$ (C-1) and the presence of 12 degree of unsaturation in 1 allowed us to conclude that as in 3 , the structure of $\mathbf{1}$ must also contain a spiro-oxindole moiety. 
The relative configurations at C-1, C-14, C-16 and C-23 of 1 were determined by NOE experiment while the absolute configurations of 1 were established by comparison of its optical rotation and CD spectroscopic data with those of 3, the absolute stereostructure of which was deduced by NMR, $\mathrm{CD}$ and X-ray diffraction crystallography analyses. The CD spectrum of $\mathbf{1}$ which displayed negative and positive Cotton effects $\left[\left(\Delta \varepsilon_{356}-0.92\right)\right.$ and $\left(\Delta \varepsilon_{242}-6.08\right)$, and $\left(\Delta \varepsilon_{265}+2.82\right)$ and $\left(\Delta \varepsilon_{229}+2.8\right)$, respectively) is superimposable with those of 3 [3].

Clopiamine C (3) belongs to the rare alkyl nitro group-bearing prenylated spirooxindole alkaloids of Penicillium species. Of this group of compounds, only cyclopiamine and citranilin-type have been reported (Figure 1) [3-6]. It is worthy to note that clopiamine C (3) and cyclopiamine B (Figure 1) are enantiomers. Their NMR spectroscopic data (although measured in different solvent) are superimposable while their reported optical rotations $\left([\alpha]_{D}\right)$ have opposite sign $\left(-97.9^{\circ}\right.$ and +117 , respectively) $[3,4]$. From these data, the absolute configurations at C-1, C-14, C-16, and C-22 were thus determined to be $S$, $R, S$, and $R$, respectively and the structure of $\mathbf{1}$ was deduced to be ent-homocyclopiamine B as depicted in Figure 2.

\section{Cyclopiamines}

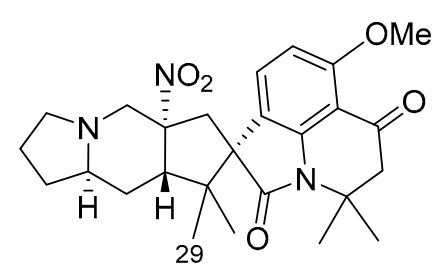

cyclopiamine A<smiles>[R]Oc1ccc2c3c1C(=O)[C@H](O)C(C)(C)N3C(=O)[C@@]21C[C@]2([N+](=O)[O-])CN3C[C@@H]4O[C@H]4C3C[C@H]2[C@]1([2H])C</smiles>

$\mathrm{R}=\mathrm{CH}_{3}$ : cyclopiamine $\mathrm{C}$ $\mathrm{R}=\mathrm{OH}$ : cyclopiamine $\mathrm{D}$<smiles>[R]C1=CC(C)(C)N2C(=O)[C@@]3(C[C@@]4([N+](=O)[O-])CN5CCC[C@H]5C[C@H]4C3([2H])[2H])c3ccc(OC)c1c32</smiles>

$\mathrm{R}=\mathrm{O}$ : cyclopiamine $\mathrm{B}$ $\mathrm{R}=\mathrm{H}, \mathrm{OH}$ : 6-hydroxycyclopiamine B<smiles>CC1(C)CC(=O)c2c(O)ccc3c2N1C(=O)[C@]31C[C@]2([N+](=O)[O-])CN3CCC[C@H]3C[C@H]2C1(C)C</smiles>

cycloexpansamine B

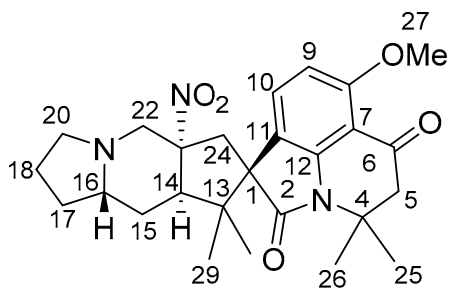

clopiamine $\mathrm{C}$ = ent-cyclopiamine $\mathrm{B}$

\section{Citranilines}<smiles>CC1(C)CC(=O)c2c(ccc3c2NC(=O)[C@]32C[C@]3([N+](=O)[O-])CN4CCC[C@H]4CC3C2(C)C)O1</smiles>

citranilin B<smiles>CC1(C)CC(=O)c2c(ccc3c2NC(=O)[C@@]32CN3CC45CCCN4CC3(C2)C5(C)C)O1</smiles>

citranilin C<smiles>CC1(C)CC(=O)c2c(ccc3c2NC(=O)[C@]32C[C@]3([N+](=O)[O-])CN4CCC[C@H]4CC3C2(C)C)O1</smiles>

citranilin A<smiles>CC1(C)CC(=O)c2c(ccc3c2NC(=O)C32C[C@]3([N+](=O)[O-])CN4CC[C@H](O)[C@H]4C[C@H]3C2(C)C)O1</smiles>

17-hydroxycitrinalin B

Figure 1. Structures of Cyclopiamines and Citranilines. 


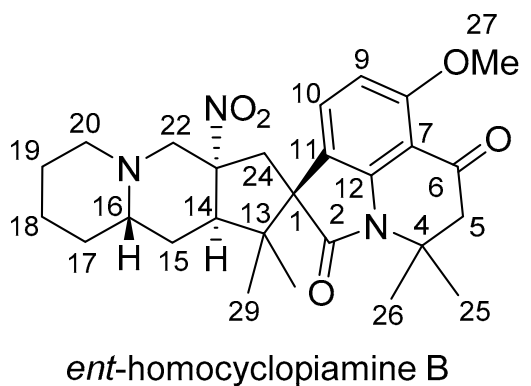

Figure 2. Structure of compound 1.

The isolation of $\mathbf{1}$ from Penicillium concentricum adds to the list of Penicillium strains that produce cyclopiamines. To determine if supplementation of sodium monofluoroacetate to the rice medium affects production of $\mathbf{1}$, an ethyl acetate extract of $P$. concentricum grown on brown rice medium and an ethyl acetate extract of the fungus fermented on brown rice supplemented with sodium monofluoroacetate were analyzed using LC-MS. Ent-homocyclopiamine B and its derivatives have been detected in the LCMS spectra of both extracts showing that the supplementation did not influence the production of compound $\mathbf{1}$. This was confirmed by positive ion electrospray LC-MS screening of the two extracts, which both displayed the peak at $m / z 482.2650$ (compound 1). Additionally, LC-MS analyses (Figure S11) of the extracts also showed a peak corresponding to the characteristic loss of a nitro-radical $(m / z$ 435.2642) from the molecular ion of $\mathbf{1}$ [3].

The possible of biosynthesis of citranilins and cyclopiamines have been studied using stable isotope $\left({ }^{13} \mathrm{C}\right)$ labelling experiments to conclude glucose, anthranilic acid and ornithine as proposed precursors [6]. The present investigation led to the isolation of mevalonic acid derived compound 2-methylbutane-1,2,3-triol (2), suggesting that the prenyl group in $\mathbf{1}$ may be introduced from the catabolism of glucose through mevalonic pathway. Lysine instead ornithine was may be involved in the biosynthesis of the indolizidine component of $\mathbf{1}$, analogous to ornithine in clopiamine $\mathrm{C}$. The clear observation of three units of isoprene and a lysine residue in the structure of $\mathbf{1}$ suggests that further investigation is needed to understand if an aminophenol related compound (apart from the reported anthranilic acid) may be involved in its biosynthesis (Figure 3).

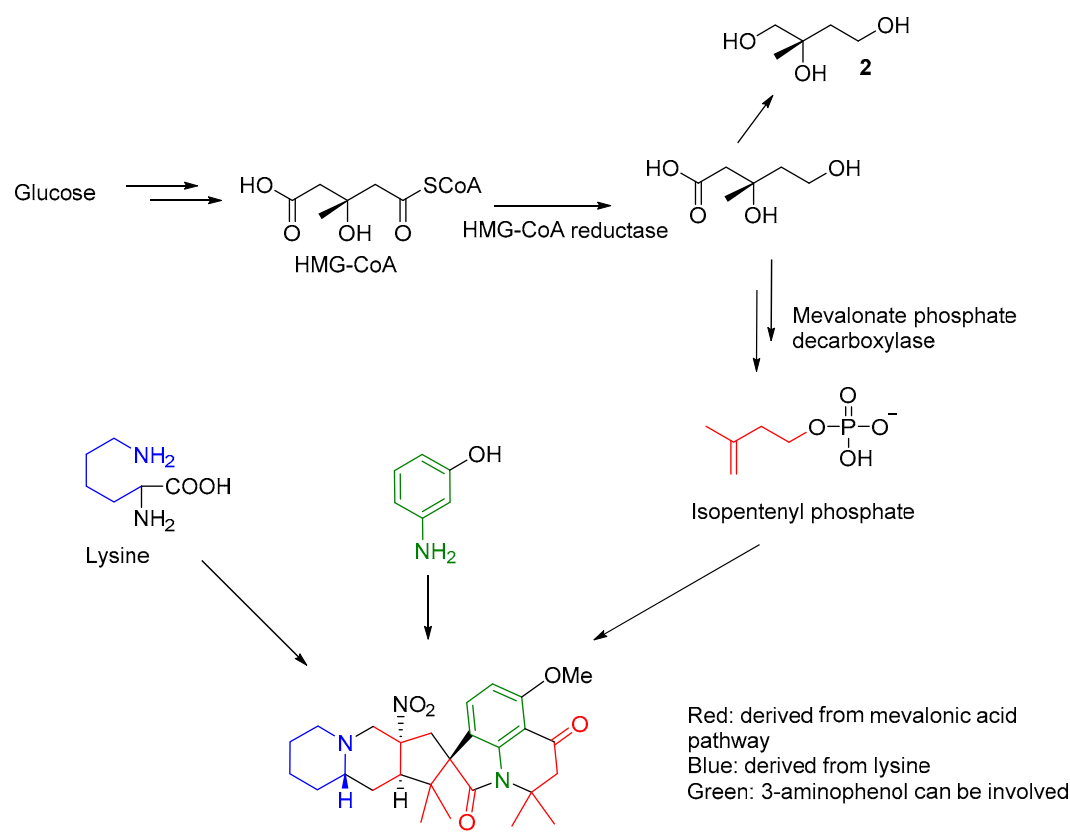

Plausible biosynthethic pathway

Figure 3. Plausible biosynthetic routes and components of $\mathbf{1}$. 
Next, the ethyl acetate fraction was subjected to fluorine NMR experiments $\left({ }^{1} \mathrm{H}\right.$ coupled and decoupled experiments). As results, the presence of fluorinated compounds was clearly observed in the two experiments performed (Data not shown). However, fluorinated compounds were not isolated during this study due to their apparent instability of during the isolation process.

\section{Antibacterial Activity of Ent-homocyclopiamine B}

Prenylated indole alkaloids have been reported to wide-ranging bioactivities including antibacterial, cytotoxic, and insecticidal properties. The antibacterial activity of $\mathbf{1}$ was tested against a panel of Gram-positive and -negative strains. Although 1 inhibited growth of Bacillus subtilis ATCC 6633 and Mycobacterium smegmatis NRRL B-14646 on agar plates, zones were significantly smaller than from an equivalent amount of kanamycin (Figure S11). Compound 1 showed no activity against Escherichia coli K12, Salmonella LT2, Micrococcus luteus ATCC 4698, Pseudomonas putida PRS2000, and Serratia marcescens NRRL B-2544 in this assay.

B. subtilis ATCC 6633, Rhodococcus jhostii RHA1, and Corynebacterium glutamicum NRRL B-2784 were partially inhibited in microbroth dilution assays with $100 \mu \mathrm{M}$ of $\mathbf{1}$ (30\% inhibition compared with background controls), but not with any concentrations below. No detectable activity was observed against any of the other tested strains.

In summary, inhibition was observed against some (but not all) of the tested Gram-positive strains. None of the tested Gram-negative bacteria were susceptible to 1 .

\section{Materials and Methods}

${ }^{1} \mathrm{H}$ and ${ }^{13} \mathrm{C}$-NMR spectra were recorded at $25{ }^{\circ} \mathrm{C}$ with a Bruker Avance III $400 \mathrm{HD}$ NMR spectrometer and Bruker Avance III HD Ascend $700 \mathrm{MHz}$. High-resolution mass spectra were acquired with a Thermo LTQ Orbitrap, specifications; analyzer: ITMS and FTMS, mass range: 50-4000 m/z, resolution: 7500-100,000. Optical rotations were determined on an Anton Paar MCP 150 polarimeter. Ultraviolet spectra (UV) were recorded using a Hitachi U-2910 UV/Vis double-beam spectrophotometer (Hitachi High- Technologies America, Schaumburg, IL, USA). Circular dichroism was measured on a Jasco J-810 spectropolarimeter. Thermo LTQ Orbitrap and Agilent 1100 HPLC were used to measure LC-MS spectra.

\subsection{Fungal Source}

Penicillium concentricum, the endophytic fungus used in this study was isolated from healthy liverwort Trichocolea tomentella and identified as previously described [1].

\subsection{Solvent Extraction and Partition of Fungal Material Fermented on Rice Medium Supplemented with Sodiummonofluoroacetate}

Eleven-days fungal culture in rice medium supplemented with sodium monofluoroacetate was soaked with $(2 \times 3 \mathrm{~L})$ EtOAc and left for overnight at room temperature. The EtOAc extract was evaporated under vacuum to yield a greenish residue $(2.3 \mathrm{~g})$. The extract residue was dissolved in methanol and partitioned with hexane $(3 \times 250 \mathrm{~mL})$ to afford $1.1 \mathrm{~g}$ of hexanes and $367 \mathrm{mg}$ of methanol fractions. The $\mathrm{MeOH}$ fraction was fractionated on $\mathrm{C}_{18}$ reversed-phase silica gel liquid chromatography using $40 \%$ aqueous methanol $(150 \mathrm{~mL})$ followed by $70 \%$ aqueous methanol $(150 \mathrm{~mL})$ and later $100 \%$ methanol to yield three fractions (B2-1, $127 \mathrm{mg}),(\mathrm{B} 2-2,78 \mathrm{mg})$ and (B2-3, $51 \mathrm{mg})$. B2-1 (127 mg) was subjected to Silica gel column chromatography $\left(2.2 \mathrm{~cm} \times 28 \mathrm{~cm}\right.$; solvent system: 15:6:1 $\left(\mathrm{CHCl}_{3}: \mathrm{MeOH}\right.$ : $\left.\mathrm{H}_{2} \mathrm{O}\right)$ ) to give six sub-fractions B2-1-1 through B2-1-6. Fraction B2-1-1 and B2-1-4 yielded compound 1 $(0.93 \mathrm{mg}$ ) and compound $2(3.7 \mathrm{mg})$, respectively.

\subsection{LC-MS Method}

LC-MS experiment was performed using Agilent 1100 HPLC binary and Thermo LTQ Orbitrap Mass spectrometer. For the HPLC, Beckman ODS column (5 m, $4.6 \mathrm{~mm}, 25 \mathrm{~cm}$, Part\#235329) heated 
at $25{ }^{\circ} \mathrm{C}$ (oven temperature). Sample was injected to a water (containing $0.1 \%$ formate)-Acetonitrile (containing $0.1 \%$ formate) gradient from $5 \%$ to $95 \%(v / v)$ over $20 \mathrm{~min}$ with a $5 \mathrm{~min}$ hold at $95 \%(v / v)$ for $5 \mathrm{~min}$. The column was then reequilibrated to $5 \%(v / v)$ for $3 \mathrm{~min}$. The flow rate was kept at $1 \mathrm{~mL} / \mathrm{min}$. Mass spectrometry aquisitions were performed using instrument settings as described in SI.

Ent-homocyclopiamine B (1): White powder, $[\alpha]_{\mathrm{D}}{ }^{25}-22.7$ (c $\left.0.1, \mathrm{MeOH}\right) ; \mathrm{CD}(\mathrm{c} 0.8, \mathrm{MeOH}) \Delta \varepsilon(\mathrm{nm})$ +2.8 (229), -6.08 (242), +2.82 (265), -0.92 (356); IR (NaCl, thin film) $v_{\max }$ : 2990, 2932, 1706, 1614, 1589, 1353, 1221, 1139; ${ }^{1} \mathrm{H}-\mathrm{NMR}$ and ${ }^{13} \mathrm{C}$-NMR spectral data, see Table 1 ; positive HRESIMS $\mathrm{m} / z 482.2643$ $\left([\mathrm{M}+\mathrm{H}]^{+}\right.$which corresponds to a molecular formula of $\mathrm{C}_{27} \mathrm{H}_{35} \mathrm{~N}_{3} \mathrm{O}_{5}$ (calcd for $\mathrm{C}_{27} \mathrm{H}_{36} \mathrm{~N}_{3} \mathrm{O}_{5}{ }^{+}, 482.2649$ ).

2-methyl-1,2,4-butanetriol (2): Colorless oil; ${ }^{1} \mathrm{H}-\mathrm{NMR}\left(400 \mathrm{MHz}, \mathrm{CD}_{3} \mathrm{OD}\right) \delta 1.19(3 \mathrm{H}, \mathrm{s}, \mathrm{H}-5), 1.76$ $(2 \mathrm{H}, \mathrm{dddd}, J=6.5 \mathrm{~Hz}, 13.9 \mathrm{~Hz}, 6.8 \mathrm{~Hz}, \mathrm{H}-3), 3.39(2 \mathrm{H}, \mathrm{dd}, J=15.5 \mathrm{~Hz}, \mathrm{H}-1), 3.39(2 \mathrm{H}, \mathrm{dddd}, J=15.5 \mathrm{~Hz}$, $6.8 \mathrm{~Hz}, 6.5 \mathrm{~Hz}, \mathrm{H}-4$ ), HRESIMS $m / z 143.0678$ (calcd for $\mathrm{C}_{5} \mathrm{H}_{12} \mathrm{NaO}_{3}{ }^{+}, 143.0684$ ).

Table 1. NMR spectroscopic data for compounds 1 and 3.

\begin{tabular}{|c|c|c|c|c|}
\hline \multirow{3}{*}{ Position } & \multicolumn{2}{|c|}{ Ent-homocyclopiamine B (1) ${ }^{a}$} & \multicolumn{2}{|c|}{ Clopiamine C (3) ${ }^{b}$} \\
\hline & ${ }^{1} \mathrm{H}$ & ${ }^{13} \mathrm{C}$ & ${ }^{1} \mathrm{H}$ & ${ }^{13} \mathrm{C}$ \\
\hline & $\delta_{H}(J$ in $\mathbf{H z})$ & $\delta_{C}$, Type & $\delta_{H}(J$ in $\mathrm{Hz})$ & $\delta_{C}$, Type \\
\hline 1 & & $62.3, \mathrm{C}$ & & $60.2, \mathrm{C}$ \\
\hline 2 & & 183.3, C & & $180.2, \mathrm{C}$ \\
\hline \multicolumn{5}{|l|}{3} \\
\hline 4 & & $57.9, \mathrm{C}$ & & $56.0, \mathrm{C}$ \\
\hline 5 & $\begin{array}{l}2.50(\mathrm{~d}, 15.6) \\
2.97(\mathrm{~d}, 15.6)\end{array}$ & $54.1, \mathrm{CH}_{2}$ & $\begin{array}{l}2.87(\mathrm{~d}, 15.0) \\
2.42(\mathrm{~d}, 15.0)\end{array}$ & 52.4, $\mathrm{CH}_{2}$ \\
\hline 6 & & $192.9, \mathrm{C}$ & & $189.4, \mathrm{C}$ \\
\hline 7 & & 108.4, C & & $106.7, \mathrm{C}$ \\
\hline 8 & & $160.2, \mathrm{C}$ & & $158.4, \mathrm{C}$ \\
\hline 9 & $6.65(d, 8.4)$ & $105.2, \mathrm{CH}$ & $6.64(\mathrm{~d}, 8.4)$ & 103.7, CH \\
\hline 10 & $7.30(\mathrm{~d}, 8.4)$ & $133.6, \mathrm{CH}$ & $7.56(\mathrm{~d}, 8.4)$ & 132.0, C \\
\hline 11 & & 122.0, C & & 118.0, C \\
\hline 12 & & $149.9, \mathrm{C}$ & & 148.0, C \\
\hline 13 & & $49.2, \mathrm{C}$ & & $48.8, \mathrm{C}$ \\
\hline 14 & $2.87(\mathrm{~m})$ & $48.8, \mathrm{CH}$ & $3.54(\mathrm{~d}, 9.0)$ & $44.0, \mathrm{CH}$ \\
\hline 15 & $\begin{array}{c}1.33(\mathrm{~m}) \\
2.77(\mathrm{td}, 12.9,6.2)\end{array}$ & $27.2, \mathrm{CH}_{2}$ & $\begin{array}{l}1.85(\mathrm{~m}) \\
1.71(\mathrm{~m})\end{array}$ & $26.8, \mathrm{CH}_{2}$ \\
\hline 16 & $3.17(\mathrm{~m})$ & $57.0, \mathrm{CH}$ & $1.92(\mathrm{~m})$ & $61.2, \mathrm{CH}$ \\
\hline 17 & $\begin{array}{c}1.58(\mathrm{qt}, 12.9,3.9) \\
1.92(\mathrm{br} \mathrm{d}, 12.5)\end{array}$ & $26.9, \mathrm{CH}_{2}$ & $\begin{array}{l}1.90(\mathrm{~m}) \\
1.21(\mathrm{~m})\end{array}$ & $30.9, \mathrm{CH}_{2}$ \\
\hline 18 & $\begin{array}{c}1.25(\mathrm{~m}) \\
1.68(\mathrm{qt}, 12.9,3.9)\end{array}$ & 21.1, $\mathrm{CH}_{2}$ & $1.63(\mathrm{~m})$ & 20.7, $\mathrm{CH}_{2}$ \\
\hline 19 & $\begin{array}{c}1.22(\mathrm{~m}) \\
1.99(\mathrm{dq}, 4.0,12.6)\end{array}$ & $26.1, \mathrm{CH}_{2}$ & $\begin{array}{l}2.87(\mathrm{~m}) \\
1.97(\mathrm{~m})\end{array}$ & 52.9, $\mathrm{CH}_{2}$ \\
\hline 20 & $\begin{array}{c}2.83(\mathrm{br} \mathrm{d}, 12.5) \\
2.86(\mathrm{~m})\end{array}$ & $56.0, \mathrm{CH}_{2}$ & & \\
\hline 21 & & & $\begin{array}{l}3.64(\mathrm{~d}, 12.6) \\
2.70(\mathrm{~d}, 12.6)\end{array}$ & 64.0, $\mathrm{CH}_{2}$ \\
\hline 22 & $\begin{array}{l}3.48(\mathrm{~d}, 11.9) \\
3.15(\mathrm{~d}, 11.9)\end{array}$ & $60.1, \mathrm{CH}_{2}$ & & $94.6, \mathrm{C}$ \\
\hline
\end{tabular}


Table 1. Cont.

\begin{tabular}{|c|c|c|c|c|}
\hline \multirow{3}{*}{ Position } & \multicolumn{2}{|c|}{ Ent-homocyclopiamine B (1) ${ }^{a}$} & \multicolumn{2}{|c|}{ Clopiamine C (3) ${ }^{b}$} \\
\hline & ${ }^{1} \mathrm{H}$ & ${ }^{13} \mathrm{C}$ & ${ }^{1} \mathrm{H}$ & ${ }^{13} \mathrm{C}$ \\
\hline & $\delta_{H}(J$ in $\mathrm{Hz})$ & $\delta_{C}$, Type & $\delta_{H}(J$ in $\mathbf{H z})$ & $\delta_{C}$, Type \\
\hline 23 & & $97.2, \mathrm{C}$ & $\begin{array}{l}2.68(\mathrm{~d}, 15.6) \\
2.61(\mathrm{~d}, 15.6)\end{array}$ & $41.3, \mathrm{CH}_{2}$ \\
\hline 24 & $\begin{array}{l}2.60(\mathrm{~d}, 16.1) \\
2.94(\mathrm{~d}, 16.1)\end{array}$ & 44.7, $\mathrm{CH}_{2}$ & $1.57(\mathrm{~s})$ & $25.6, \mathrm{CH}_{3}$ \\
\hline 25 & $1.70(\mathrm{~s})$ & $26.8, \mathrm{CH}_{3}$ & $1.26(\mathrm{~s})$ & $23.2, \mathrm{CH}_{3}$ \\
\hline 26 & $1.40(\mathrm{~s})$ & $23.7, \mathrm{CH}_{3}$ & $3.79(\mathrm{~s})$ & $55.8, \mathrm{CH}_{3}$ \\
\hline 27 & $3.80(\mathrm{~s})$ & $56.5, \mathrm{CH}_{3}$ & $0.97(\mathrm{~s})$ & $22.8, \mathrm{CH}_{3}$ \\
\hline 28 & $0.95(\mathrm{~s})$ & $24.4, \mathrm{CH}_{3}$ & $0.87(\mathrm{~s})$ & $22.8, \mathrm{CH}_{3}$ \\
\hline 29 & $0.82(\mathrm{~s})$ & $23.5, \mathrm{CH}_{3}$ & & \\
\hline
\end{tabular}

a $700 \mathrm{MHz}$ for ${ }^{1} \mathrm{H}-\mathrm{NMR}$ and $150 \mathrm{MHz}$ for ${ }^{13} \mathrm{C}$, measured in $\mathrm{CD}_{3} \mathrm{OD}-d_{4},{ }^{\mathrm{b}}$ From reference [3].

\subsection{Antibacterial Testing}

Assayed strains included Escherichia coli K12, Salmonella enterica serovar Typhimurium LT2, Pseudomonas putida PRS2000, Serratia marcescens NRRL B-2544, Bacillus subtilis ATCC 6633, Micrococcus luteus ATCC 4698, Mycobacterium smegmatis NRRL B-14616, Corynebacterium glutamicum NRRL B-2784, and Rhodococcus jhostii RHA1. Strains PRS2000, ATCC 4698 and RHA1 were grown on nutrient broth (5 g peptone, $3 \mathrm{~g}$ meat extract, per L) at $30{ }^{\circ} \mathrm{C}$ and all others on $\mathrm{LB}(5 \mathrm{~g} \mathrm{NaCl}, 5 \mathrm{~g}$ yeast extract, $10 \mathrm{~g}$ tryptone, per $\mathrm{L})$ at $37^{\circ} \mathrm{C}$. Bacto agar $\left(16 \mathrm{~g} \mathrm{~L}^{-1}\right)$ was added for plates.

Growth inhibition was evaluated on plates inoculated with lawns of the test strains. $50 \mu \mathrm{L}$ of an overnight culture of bacteria was added to $5 \mathrm{~mL}$ of broth and grown until the culture reached a turbidity equal to $1 \times 10^{7}-2 \times 10^{8} \mathrm{CFU} / \mathrm{mL}$ (based on a previously determined calibration curve). $100 \mu \mathrm{L}$ was then evenly spread onto plates using sterile glass beads to dryness. 50 nmoles ent-homocyclopiamine $\mathrm{B}$ (dissolved in $5 \mu \mathrm{L} 25 \%$ DMSO), 50 nmoles kanamycin (dissolved in $5 \mu \mathrm{L}$ water), or diluent controls ( $5 \mu \mathrm{L}$ of sterile water or $5 \mu \mathrm{L} 25 \%$ DMSO) were applied, allowed to dry, and then incubated for $16-20 \mathrm{~h}$ at the growth temperature appropriate for each strain.

The broth microdilution assay was performed as outlined by the Clinical and Laboratory Standards Institute (CLSI) [7]. Briefly, $2 \mu \mathrm{L}$ of a 50X stock of ent-homocyclopiamine B (dissolved in $25 \%$ DMSO) was added to wells of a 96-well plate. Live and background controls received $2 \mu \mathrm{L}$ of diluent. $88 \mu \mathrm{L}$ of broth was added to all wells except background control wells which received $98 \mu \mathrm{L} .50 \mu \mathrm{L}$ of an overnight culture of bacteria was added to $5 \mathrm{~mL}$ of broth and grown until the culture reached a turbidity equal to $1 \times 10^{7}-2 \times 10^{8} \mathrm{CFU} / \mathrm{mL}$ (based on a previously determined calibration curve). The culture was diluted to $5 \times 10^{6} \mathrm{CFU} / \mathrm{mL}$ and $10 \mu \mathrm{L}$ added to each well except background controls to a final concentration of $5 \times 10^{5} \mathrm{CFU} / \mathrm{mL}$. Plates were incubated at $30{ }^{\circ} \mathrm{C}$ or $37^{\circ} \mathrm{C}$ (as appropriate for each strain) for 16-20 h. Absorbance was then recorded on a Bio-Rad xMark microplate spectrophotometer at $\lambda=600 \mathrm{~nm}$. Minimal inhibitory concentration (MIC) values were defined as the lowest concentration resulting in $\geq 90 \%$ growth inhibition.

Supplementary Materials: The following are available online. NMR, CD spectra, LCMS and fluorine NMR of the extracts.

Author Contributions: Conceptualization, H.L.R. methodology, T.A., H.L.R., T.M.P., K.-S.J.; formal analysis, T.A., T.M.P., K.-S.J., H.L.R.; investigation, T.A. T.M.P.; writing-original draft preparation, T.A.; writing-review and editing, K.-S.J., H.L.R.; supervision, K.-S.J., H.L.R.; funding acquisition, H.L.R.

Funding: This work was partially supported by: The Ohio State Comprehensive Cancer Center Seed Grant to one of the authors (H.L.R.): Grant \# IRG-67-003-50 from the American Cancer Society and A supplement of the program grant P01 CA125066-10S1 (H.L.R). We also wish to thank the Libyan government for providing a scholarship to Ms. T. Ali. 
Acknowledgments: We thank The Ohio State University, CCIC and the College of Pharmacy, instrumentation facility for the acquisition of the NMR and mass spectra.

Conflicts of Interest: The authors declare no conflict of interest.

\section{References}

1. Ali, T.; Inagaki, M.; Chai, H.; Wieboldt, T.; Rapplye, C.; Rakotondraibe, L.H. Halogenated Compounds from Directed Fermentation of Penicillium concentricum, an Endophytic Fungus of the Liverwort Trichocolea tomentella. J. Nat. Prod. 2017, 80, 1397-1403. [CrossRef] [PubMed]

2. Gill, M.; Harte, M.F.; Ten, A. Pigments of fungi. LIX synthesis of (1S,3S)- and (1R,3R)-austrocortilutein and (1S,3S)-austrocortirubin from citramalic acid. Aust. J. Chem. 2000, 53, 245-256. [CrossRef]

3. Zhang, D.W.; Zhao, L.; Wang, L.; Fang, X.; Zhao, J.; Wang, X.; Li, L.; Liu, H.; Wei, Y.; You, X.; Cen, S.; Yu, L. Griseofulvin Derivative and Indole Alkaloids from Penicillium griseofulvum CPCC 400528. J. Nat. Prod. 2017, 80, 371-376. [CrossRef] [PubMed]

4. Bond, R.F.; Boeyens, J.C.A.; Holzapfel, C.W.; Steyn, P.S. Cyclopiamines A and B, novel oxindole metabolites of Penicillium cyclopium westling. J. Chem. Soc. Perkin. Trans. 1979, 1, 1751-1761. [CrossRef]

5. Kildgaard, S.; de Medeiros, L.S.; Phillips, E.; Gotfredsen, C.H.; Frisvad, G.C.; Nielsen, K.F.; Abreu, L.M.; Larsen, T.O. Cyclopiamines C and D: Epoxide Spiroindolinone Alkaloids from Penicillium sp. CML 3020. J. Nat. Prod. 2018, 81, 785-790. [CrossRef] [PubMed]

6. Mercado-Marin, E.V.; Garcia-Reynaga, P.; Romminger, S.; Pimenta, E.F.; Romney, D.K.; Lodewyk, M.W.; Williams, D.E.; Andersen, R.J.; Miller, S.J.; Tantillo, D.J.; et al. Total synthesis and isolation of citrinalin and cyclopiamine congeners. Nature 2014, 509, 318-324. [CrossRef] [PubMed]

7. Patel, J.B.; Cockerill, F.R.; Bradford, P.A.; Elipoulos, G.M.; Hindler, J.A.; Jenkins, S.G.; Lewis, J.S.; Limbago, B.; Miller, L.A.; Nicolau, D.P.; et al. Methods for Dilution Antimicrobial Susceptibilities Tests for Bacteria That Grow Aerobically, Approved Standard-Tenth Edition; Clinical and Laboratory Standards Institute: Wayne, PA, USA, 1990.

Sample Availability: Samples of the compounds are not available from the authors due to the scarce amount of the isolated compounds.

(C) 2019 by the authors. Licensee MDPI, Basel, Switzerland. This article is an open access article distributed under the terms and conditions of the Creative Commons Attribution (CC BY) license (http://creativecommons.org/licenses/by/4.0/). 